REVISTA DE DERECHO UNED, NÚM. 17, 2015

\title{
EL PRINCIPIO NEMO PRO PARTE TESTATUS PRO PARTE INTESTATUS DECEDERE POTEST: ESTUDIO SOBRE EL ORIGEN, EVOLUCIÓN Y TRASCENDENCIA EN EL ORDENAMIENTO JURÍDICO ACTUAL
}

\begin{abstract}
THE PRINCIPLE NEMO PRO PARTE TESTATUS PRO PARTE INTESTATUS DECEDERE POTEST: STUDY OF ORIGINS, EVOLUTION AND SIGNIFICANCE IN THE CURRENT LEGAL SYSTEM
\end{abstract}

\author{
ANTONIO GÓMEZ RÓDENAS \\ Máster EEES Familia y Sucesiones UNED ${ }^{1}$ \\ Abogado
}

Resumen: El principio Nemo Pro Parte Testatus Pro Parte Intestatus Decedere Potest, o simplemente Nemo Pro Parte, es un principio que establece la incompatibilidad entre la sucesión testada e intestada. Su origen histórico constituye todavía un objeto de discusión por la romanística y aunque fue abolido por el derecho histórico castellano, pervive en el Derecho catalán por razones de carácter histórico.

La distinta evolución del Derecho en España, produjo que el derecho castellano se desarrollase con la confluencia de los principios sucesorios germánicos y romanos y así queda plasmado en el actual Código Civil español. Sin embargo, la persistencia del principio en Cataluña generó críticas a la inexistente evolución del principio. Críticas que hoy siguen presentes.

\footnotetext{
${ }^{1}$ Agradezco al Departamento de Derecho civil de la UNED, y a su Director, Prof. Carlos Lasarte y a su discípula, la Profesora Moretón Sanz, el apoyo que me han prestado y muy especialmente la revisión y supervisión de este trabajo.
} 
Abstract: The principle Nemo Pro Parte Testatus Pro Parte Intestatus Decedere Potest, or just Nemo Pro Parte, is a principle that establishes the incompatibility between testate and intestate succession. The historical origin is still a subject of discussion for the civil law studies and although it was abolished by the castilian historical right, survives in the catalan law for historical reasons.

The different evolution of the law in Spain produced for the castilian law will evolve with the confluence of the germanic and roman principles. It is reflected in the actual Spanish Civil Code. However, the persistence of the principle in Catalonia drew criticism about the non-existent evolution of the principle. Criticisms are still present.

Palabras clave: Sucesión testada e intestada. Principio Nemo Pro Parte.

Keyword: Testate and intestate succession. Principle Nemo Pro Parte.

Recepción original: 16/06/2015

Aceptación original: 24/07/2015

Sumario: I. Introducción; II. Los orígenes de la incompatibilidad entre la sucesión testamentaria y la intestada en el Derecho Romano. 1. Antecedentes. el principio como valor 2. Origen del principio de incompatibilidad entre la sucesión testamentaria e intestada. III. La evolución en el Derecho Castellano Del Principio Nemo Pro Parte. IV. La compatibilidad e incompatibilidad entre la sucesión testamentaria y la intestada en el Ordenamiento Jurídico Español actual. V. Conclusiones. VI. Bibliografía. VII. Resoluciones citadas.

\section{ABREVIATURAS}

A.C. Antes de Cristo.

Cc. Código Civil.

CCCat Código Civil de Cataluña.

D. Digesto.

I. Instituciones de Justiniano.

LSI Ley Catalana de Sucesión Intestada (1936).

STS Sentencia del Tribunal Supremo.

STSJC Sentencia del Tribunal Superior de Justicia de Cataluña.

STC Sentencia del Tribunal Constitucional. 


\section{INTRODUCCIÓN}

El propósito del presente estudio es realizar un recorrido por los orígenes del principio romano de incompatibilidad entre la sucesión testada e intestada y revisar como éste ha condicionado el proceso de evolución de los ordenamientos jurídicos en materia de Derecho hereditario.

Antes de acercarnos al fundamento del principio, indagaremos en los antecedentes más lejanos que pudieran explicar el fundamento de esta regla puesto que, como veremos, tras la caída del Imperio romano los juristas la aplicaron sin entender sus raíces y justificación.

Dedicaremos un primer apartado a hablar de la sucesión en el Derecho romano, su evolución desde la Ley de las XII Tablas hasta la aparición de los primeros testamentos, susceptibles de haber sido regidos por el principio nemo pro parte.

Tras la caída del Imperio y la disgregación de las grandes fuerzas europeas, el medioevo dio pie a la adopción de la incompatibilidad por el derecho de los pequeños feudos. En el caso que nos ocupa, trataremos las coronas peninsulares y sus distintos procesos de adaptación y aplicación. Como segundo apartado trataremos la evolución del principio en Castilla, desde el siglo XV que se dirigió en una línea que culminó con su desaparición expresa en el siglo XIX, circunstancia que no se dio, por ejemplo, en las tierras regidas bajo las leyes catalano-aragonesas, donde el apego a las reglas romanas permitió su pervivencia hasta la actualidad. Ello puede comprobarse en el Código de Sucesiones catalán que lo mantiene, sin justificación jurídica, pero bajo presupuestos de continuidad histórica. Por su parte, el Derecho aragonés, autoriza la compatibilidad entre los distintos modos de sucesión, tal y como se recoge en su nuevo texto refundido ${ }^{2}$.

Finalmente, reflexionaremos sobre la situación actual y su aplicación en las tierras catalanas y cómo afecta la aplicación de un principio atemporal a la sociedad contemporánea.

El conjunto del estudio pretende ser una suerte de compendio de las más importantes publicaciones en relación a esta materia, reflexionando acerca del origen y concluyendo y confluyendo con aque-

${ }^{2}$ Artículo 317. Modos de delación. 1. La sucesión se defiere por pacto, por testamento o por disposición de la ley. 2. Los distintos modos de delación son compatibles entre sí (Decreto Legislativo 1/2011, de 22 de marzo, del Gobierno de Aragón, por el que se aprueba, con el título de "Código del Derecho Foral de Aragón», el Texto Refundido de las Leyes civiles aragonesas). 
llos autores que han marcado las pautas a seguir en la comprensión del principio Nemo Pro Parte.

\section{LOS ORÍGENES DE LA INCOMPATIBILIDAD ENTRE LA SUCESIÓN TESTAMENTARIA Y LA INTESTADA EN EL DERECHO ROMANO}

\section{Antecedentes. El principio como valor}

Con carácter previo al análisis del principio en sí, debemos rescatar en el contexto y marco histórico, la situación en la que se fijó la incompatibilidad entre la sucesión testamentaria e intestada. Por su parte, los romanistas no tienen duda de que el principio se desarrolló con la aparición de la forma de testamento conocido como testamentum per aes et libram, pero que la ratio que lo justifica puede remontarse a los orígenes del propio fundamento de la sucesión. Por ello, creemos necesario elevarnos al concepto de heres y desarrollar desde dicho punto la reiterada incompatibilidad en el Derecho romano.

El Derecho sucesorio romano conforma un todo armónico, y esta armonía emerge del encaje perfecto existente entre todos los principios que regían en la antigua Roma. Principios profundamente concatenados entre sí y relacionados en sus efectos.

El Principio que tratamos es la lógica y natural consecuencia de los demás principios reguladores de la sucesión romana. Así, en todo testamento ha de existir institución de heredero, si el que es heredero lo es siempre, y si al heredero acrece la porción vacante de la herencia. En definitiva, tres elementos: Existencia; Perdurabilidad y Universalidad atañen a la institución del heredero. Esa es la verdadera razón de ser del Principio Nemo Pro Parte, dar coherencia al conjunto del ordenamiento, como norma y valor.

Cuando hablamos de la incompatibilidad como valor, hacemos referencia a la importancia que tenía en la antigua Roma -y posteriormente en la acogida del principio en periodo medieval- como principio regulador del orden público romano. De una parte, el poder absoluto del «pater familias» debía perpetuarse y el conjunto de circunstancias sociales debían mantenerse. El derecho hereditario romano era propio de una clase, la de los patricios o terratenientes, para la 
cual la conservación de la hacienda familiar era de importancia decisiva como fundamento del poder político ${ }^{3}$.

La concepción romana de la familia debe ser entendida como un organismo político. En Roma, la designación de un heredero, de un cabeza de familia, era fundamental para la continuación de la familia y una consecuencia de esta designación era la adquisición del patrimonio del causante. En este sentido LACRUZ explica el concepto de heredes sui, afirmando que «el heredero no recibe, no recoge, no realiza la aditio; es la domus la que se perpetúa en él».

Entender el principio como valor, pasa por determinar que hay tres características básicas en el Derecho sucesorio romano: Unidad del título sucesorio; Perdurabilidad del título sucesorio y Universalidad del heredero. Para el tema que nos ocupa en el estudio, solo trataremos la unidad del título sucesorio (Nemo Pro Parte). Sin embargo, cuando nos ocupemos de la pervivencia del principio en Cataluña, nos será imposible obviar estos aspectos.

Además, para comprender el alcance de la regla, debemos atender a su fundamento y origen y por qué en determinado momento prevaleció la sucesión testada sobre la intestada. Sin embargo, cabe responder a este interrogante previo ¿cuál de las dos formas de sucesión (testada o intestada) apareció, temporalmente, en primer lugar? La doctrina está sumamente dividida y los romanistas adoptan una u otra posición según la interpretación histórica que se tome.

En este sentido, PACCHIONI basándose en la búsqueda de la naturaleza de la primitiva hereditas confía en que si ésta tenía un carácter político, es totalmente ilógico que el heredero fundara su soberanía en dos títulos diversos, títulos que, además, podían resultar contrapuestos. Esta misma línea sigue PÉREZ SIMEÓN, quien analiza con precisión y minuciosidad el concepto de heres en relación a la incompatibilidad.

Como bien apunta PÉREZ SIMEÓN ${ }^{4}$, el concepto de heres como sucesor universal nace en el marco de la sucesión intestada, con carácter previo a la creación de cualquiera de las formas testamentarias

\footnotetext{
${ }^{3}$ En relación al Derecho Sucesorio Catalán, la pervivencia del Principio Nemo Pro Parte se justificará por la necesidad de transmitir las propiedades agrarias de los terratenientes catalanes. Equiparando y modernizando uno de los fundamentos esenciales de la antigua Roma la legislación sucesoria catalana. Reza la disposición catalana en su preámbulo «no s’ha considerat oportú alterar-los».

${ }^{4}$ PÉREZ SIMEÓN M. En «Nemo Pro Parte Testatus Pro Parte Intestatus Decedere Potest», El principio de incompatibilidad, entre la sucesión testamentaria y la intestada en el Derecho Romano, Marcial Pons, Barcelona, 2001, pág. 15.
} 
más arcaicas de las que tenemos noticia. En una primera época, solo la ley confería el título de heres. Esta palabra latina se encuentra y en las XII Tablas (Tabula V,4) ${ }^{5}$, aunque el concepto es, sin duda, anterior.

Por su parte, PUIG I FERRIOL concibe al heredero como el personaje central entorno al que gira la totalidad del proceso sucesorio, recordando a ULPIANO cuando expresaba que se podía otorgar testamento con tres escasas palabras «sea heredero Ticio». En la actualidad resultaría imprescindible agregar algunos requisitos formales, pero el heredero continuaría siendo una figura clave y obligatoria en algunas normativas como la catalana.

La Ley de las XII Tablas considera solo a los hijos en potestad como heredes. El heres por tanto, es aquel hijo que accede al caudal hereditario, asumiéndolo en bloque y de forma automática, tanto el activo como el pasivo.

En el S. v A.C., podemos hablar ya de una apropiación individual de objetos económicamente valiosos. La Ley de las XII Tablas, como veremos más adelante, preveía la posibilidad de adquirir y disponer de bienes concretos sin diferenciar entre patricios o plebeyos. En el texto decenviral se encontraban, por ejemplo, las normas que servían de fundamento a la actio familiae erciscundae a la actio finium regundorum y a la mancipatio.

Como hemos anticipado, la Ley de las XII Tablas menciona al heredes sui y sobreentiende que los sui son la primera clase de sucesores $a b$ intestato. Si hay heredes sui, resulta necesario admitir la existencia de otros heredes que eran alieni, ya que, de otra forma, el posesivo sus habría sido absolutamente innecesario ${ }^{6}$.

No es probable que la Ley de las XII Tablas dedicara un apartado exclusivo a la adquisición mediante apropiación exclusiva de los bienes de uso y consumo con un derecho ad hoc, por lo sin duda ha de referirse a un objeto de mayor calado. La Ley de las XII Tablas centra su atención en esta institución y a los negocios relacionados con ella con una pretensión clara y es que el patrimonio se transmitiera mortis causa. En el S. v A.C., existe una importante cantidad de bienes, incluidos medios de producción (res mancipi), que pertenecían a los paterfamilias de forma exclusiva, que eran enajenables inter vivos y que eran transmisibles mortis causa.

${ }^{5}$ Tabula $V$,4. «Si intestato moritur, cui suus heres nec escit adgnatus proximus familiam habeto. Si adgnatus nec excit, gentiles familiam -habento- (RICCOBONO, Fontes iuris Romani anteiustiniani. Pars Prima, 1968, p.38).

${ }^{6}$ (Vid. Tabula V,4). 
Como refiere PÉREZ SIMEÓN, es improbable que la Ley esté pensando en los agnati proximi o en los gentiles, puesto que parte del fundamento de la Ley es evitar las distinciones entre dichas clases. La Ley de las XII Tablas dice de ellos familiam habento y no heredes sunto, y siguiendo la opinión de SCHERILLO, en el S. v A.C., las personas pertenecientes a estos grupos no recibían el calificativo de heredes ${ }^{7}$. En época clásica, la diferencia arcaica entre heres ese y familiam habere se ha diluido, y tanto los sui como los agnati proximi son heredes, de forma que es imposible determinar cuál era la diferencia sustancial entre estos dos conceptos en las XII Tablas. Solo puede afirmarse con seguridad que la distinta denominación no puede ser casual.

Si los heredes que no son sui no pueden ser ni los agnados próximos ni los gentiles, solo cabe entender que la Ley está remitiéndose a aquellos que aparecen en el testamento. Nadie niega que en la época de las XII Tablas existiera el concepto de testamento, palabra de por sí antigua, que etimológicamente puede ser reconocida en el vocablo osco trístaamentud, puesto que la palabra intestato presupone necesariamente la existencia de esta institución. Sin embargo, la dificulta queda evidenciada cuando pretendemos determinar qué entiende la Ley por testamento.

En opinión de PÉREZ SIMEÓN, los tipos de testamento a los que se contrapone el término intestato son el testamentum calatis comitiis y, quizás, también el testamentum in proncinctu.

El testamentum in proncinctu aparece citado en un escrito de Cicerón, así como en un fragmento de Sabidio a la Eneida, que nos confirma su condición de testamento especial para soldados antes de la batalla. A partir del análisis de dichos documentos, parece que era un testamento que podían otorgar los militares antes de entrar en combate. Es posible que se tratara de un testamento con las mismas características que el testamentum calatis comitiis, en el que el ejército sustituyera a las curias en su función institucional.

En cualquier caso, este tipo de testamento no tiene ninguna relación con el testamentum militis de la época clásica puesto que desaparecería en el S. II A.C. y trataría otro aspecto.

En relación al testamentum calatis comitiis, éste podía realizarse ante los comicios curiados en dos días determinados al año. Por analogía con el procedimiento de la adrogatio, que también tenía lugar ante los comicios, es muy probable, según los romanistas más entendidos, que las curias tuvieran que dar su aprobación y no actuaran como meros testigos. Es plausible que el testamento comicial solo

\footnotetext{
${ }^{7}$ SCHERILLO, Il testamento. Corso di diritto romano, Milán, 1995, p.103.
} 
pudiera ser otorgado por patricios, ya que, al parecer, los plebeyos no participaban en los comitia curiata. Como apuntan algunos autores, este tipo de testamento venía a ser una «lex specialis» que abrogaba la ley general de la sucesión ab intestato.

Nos parece muy interesante la interpretación de VOCI cuando encuentra en este hecho la razón por la que las XII Tablas no hablen expresamente del testamento comicial. Dado que esta Ley tiene como finalidad igualar los derechos entre patricios y plebeyos, pasa de largo por un privilegio que los patricios deseaban conservar en exclusiva.

Y es que la necesidad de continuar con el culto familiar y la propia estirpe fue un aspecto mucho más importante en los patricios que en los plebeyos en la época en la que nos situamos. Esto se corrobora en que la facultad de testar y de adrogar no fue una de las reivindicaciones de los plebeyos en las rebeliones constantes que darían lugar a la redacción de las XII Tablas.

El parecido entre el testamentum calatis comitiis nos lleva a establecer un nexo entre estas dos instituciones. Sin embargo, no queda claro qué aspectos se diferenciaban entre una institución y otra, aunque es bastante seguro que nunca fueran exactamente los mismos, ya que el testamento introducía, por lo menos, la especialidad de retrasar la eficacia del acto hasta el momento de la muerte del testador. Para algunos, toda la especialidad del testamento comicial radicaba en este hecho, de forma que el testamentum calatis comitiis no sería más que una adrogación con efectos retardados al momento de la muerte del adrogante. Se colocaba al adrogado en la posición jurídica de un sus, para que pudiera suceder como tal ${ }^{8}$.

Es probable que en sus orígenes, el testamentum calatis comitiis se concibiera, de esta forma, y que comportara la detestatio sacrorum por parte del adrogado en el acto ante los comicios. No debemos ignorar que muchos pueblos de la antigüedad solventaban los conflictos en sede de transmisión mortis causa, en casos de paterfamilia sin descendencia, mediante el sistema de la adrogatio, con el fin de dar respuesta a una realidad y mantener los sacra. Teniendo en cuenta esto, es indudable que el Derecho comparado apoya decididamente esta hipótesis. Sin embargo, cuando se redactan las XII Tablas, el heres de un testamento comicial no ocupaba exactamente la idéntica posición jurídica que los hijos en potestad. El instituido en el testamento comicial no se convertía automáticamente en

\footnotetext{
${ }^{8}$ Algunos romanistas como LAMBERT hablan del origen del principio de incompatibilidad entre las sucesiones testamentaria e intestada en esta equiparación del testamentoadrogación. Para ahondar en dicho aspecto, vid., LAMBERT, La tradición romana sobre la sucesión de formas del testamento ante la historia comparada, Madrid, 1901, págs. 97y ss.
} 
suus heres. La denominación heredes sui se reserva a los hijos en potestad y no se aplica a los herederos testamentarios. En otro caso, no habría hecho falta que las XII Tablas dijeran «Si intestato moritur, cui suus heres nec escit...» porque morir testado habría implicado tener suus heres.

Lo más probable es que el testamento comicial, estrechamente ligado con la adrogación, solo fuera accesible en todas las épocas, a los padres de familia patricios sin descendientes. Era una manera de conseguir que la persona sin descendencia pudiera designar a un sucesor que adquiriera su patrimonio y continuara el culto familiar. Sin embargo, tampoco es descabellada la hipótesis propuesta por LAMBERT de la doble función del testamento calatis comitiis. Por un lado, habría dado la posibilidad de instituir un heredero al paterfamilias sin descendientes y, por otro lado, también habría permitido al padre de familia con demasiados hijos elegir a uno para evitar la dispersión del patrimonio. En cualquier caso, no parece que el testamento comicial pudiera contener la institución de una pluralidad de herederos, ni, en consecuencia, distribución de cuotas. Tampoco parece que se pudieran ordenar legados. Como apunta PEREZ SIMEÓN, el testamentum calatis comitiis se mantuvo, con toda probabilidad, excesivamente apegado al negocio adrogatorio como para permitir todo esto.

En el S. V A.C. ya podemos decir que el testamento comicial se había convertido en un acto por el que un paterfamilias patricio, sin hijos podía instituir un heres. El otorgamiento del título de heres no se hacía ya indirectamente, a través de la adquisición de la categoría de suus, sino directamente, en virtud del testamento.

Sin embargo, el testamento comicial no era el único modo de controlar el destino de las propias cosas para después de la muerte en la época de las XII Tablas puesto que era necesario que existiera también un acto independiente de disposición mortis causa de bienes a título particular. Con ello podemos explicar el sentido de la famosa frase del texto decenviral (Tabula V 3).

"Uti legassit suae rei, ita ius esto»9

Como apunta WLASSAK, con esta frase, las XII Tablas permitían a los ciudadanos romanos disponer a título particular mortis causa

9 «La très ancienne succession romaine interpretée d'après le droit compare», $R H$, 32, 1954, págs. 500-ss, en Los orígenes de la Incompatibilidad de PÉREZ SIMEÓN, "Nemo Pro Parte Testatus Pro Parte Intestatus Decedere Potest», El principio de incompatibilidad, entre la sucesión testamentaria y la intestada en el Derecho Romano, Marcial Pons, Barcelona, 2001. La cita puede no ser precisa puesto que las distintas fuentes han dado lugar a diferentes versiones. Es probable que en época preclásica y clásica la frase tomara formas diversas. 
de sus objetos personales (enseres personales y diversos bienes de especial aprecio, tales como armas o vestimentas). Como antes exponíamos, los actos de disposición de bienes mortis causa a título particular son frecuentes en los Derechos de los pueblos indoeuropeos ${ }^{10}$.

Podemos afirmar que este acto no recibía la denominación de testamentum, que no permitiría instituir herederos y que era completamente independiente del testamento comicial. La Ley de las XII Tablas no distingue entre patricios y plebeyos en la frase uti legassit ${ }^{10}$. Por otro lado, parece probable que el testamento comicial solo estuviera al alcance de los padres de familia sin descendientes. Es difícil aceptar que la posibilidad de legar objetos personales se hubiera restringido a las personas que tenían la desgracia de no tener sui heredes (este acto desapareció seguramente con la introducción del testamento libral).

Así pues, en la época de las XII Tablas, solo se podía instituir heredero en el testamentum calatis comitiis. Probablemente, y en exclusiva, el paterfamilias patricio sin hijos era quien podía otorgar este tipo de testamento que, originariamente, consistía en una adrogación con eficacia suspendida hasta el momento de la muerte del causante. Con toda probabilidad podía designarse un único heredero. Además de este testamento, existía la posibilidad de disponer de bienes concretos en un acto cuyo nombre desconocemos, refrendado en las XII Tablas con la frase uti legassit...

Posteriormente, la jurisprudencia pontifical introdujo la mancipatio familiae, una nueva forma de disposición de los bienes familiares para después de la muerte. Gayo, única fuente de la mancipatio, la recoge en sus Instituciones conjuntamente con el testamentum per aes et libram porque la ve como su antecedente inmediato.

Sin embargo, a pesar de que podemos advertir una notable influencia en el testamento libral de la mancipatio familiae, no debe llevarnos a error puesto que, aún con el tratamiento conjunto de Gayo, todo lo que respecta a la forma, muestra que son instituciones esencialmente distintas y deben ser expuestas, por ello, de forma separada.

En relación a la mancipatio familiae: La jurisprudencia pontifical, con el fin de dar solución a la problemática de que solo se pudiera

\footnotetext{
${ }^{10}$ No podemos precisar el funcionamiento de este negocio, ni las formalidades a las que estaba sometido, porque no tenemos otra fuente que nos informe de él, salvo la citada frase de las XII Tablas.
} 
testar en determinados días o bajo determinadas circunstancias (ser patricio; no tener descendencia) ideó una forma de adaptar la mancipatio para permitir a todo paterfamilias elegir el destino de su patrimonio después de su muerte. A través de una mancipación se transmite en bloque todo el patrimonio a un fiduciario (amicus) y se le encarga su distribución. Esta transmisión en bloque solo era posible, en un primer momento, con efectos inmediatos, de forma que el testador moría sin patrimonio. Por eso testaba cuando súbita norte urguebatur ${ }^{11}$.

GAYO no nos transmite la fórmula de la mancipatio familiae, sino que reproduce la que en su época se utilizaba para otorgar un testamentum per aes et libram. Aunque no es fácil determinar en qué medida esta fórmula coincide con la que se utilizaba originalmente para la mancipatio familiae, hay dos incisos que difícilmente debían de estar en la fórmula originaria.

En primer lugar, no es probable que en la mancipatio familiae se pronunciara la frase quo-puplicam puesto que con ella se afirma expresamente que la mancipación no pretende transmitir la propiedad, que es su función originaria, sino que tan sólo es un ritual que sirve para que el testador pueda otorgar testamento de acuerdo con el Derecho. Estas palabras debieron de introducirse al adaptar las formalidades de la mancipatio familiae al testamentum per aes et libram.

Las palabras ita testor quizás tampoco se pronunciaran en la mancipatio familiae, ya que resultan una repetición de itaque-perhibetote. En cualquier caso, de ita testor no puede deducirse que la mancipatio familiae sea un testamentum en el que hubiera un heres instituido. La razón por la que Gayo llama testador al mancipio dans es por el tratamiento conjunto que realiza de ambas instituciones.

Además, GAYO apunta en sus Instituciones que el amicus (el familiae emptor) se encontraba heredis loco y por eso distribuía los bienes entre los beneficiarios ${ }^{12}$. Por tanto, es un titular fiduciario del patrimonio del difunto, que ha adquirido en bloque. Su función es pagar las deudas, distribuir los bienes de acuerdo con la voluntad del testador, y cumplir y hacer cumplir sus encargos.

${ }^{11}$ Más tarde, sin embargo, se permitiría retrasar los efectos de la transmisión al fiduciario al momento de la muerte del testador (PÉREZ SIMEÓN, M.).

${ }^{12}$ Es importante tener en cuenta que aunque en algunos aspectos sus funciones se aproximen a las del heredero, el familiae emptor no es un heres (PÉREZ SIMEÓN, M.).

(C) UNED. Revista de Derecho UNED, núm. 17, 2015 
En el Derecho romano, la mancipatio familiae es la única forma de organizar la sucesión por causa de muerte que prescinde del concepto de heres. Ni el familiae emptor, ni los beneficiarios de las atribuciones que el testador le ha encomendado, son heredes. Cuando un paterfamilias realiza una mancipatio familiae, los heredes siguen siendo los sui. Éstos no heredarán, sin embargo, bien alguno, porque el testador muere sin patrimonio. Si el testador muere sin sui, no tendrá heredes.

La función de la mancipatio familiae es dejar ineficaz la sucesión legal, eliminando su objeto (la hereditas) justo antes de que tenga lugar la apertura de la sucesión. La principal ventaja que presenta respecto del acto mortis causa al amparo de la frase uti legassit... debía ser el objeto sobre el que podía disponerse.

Esto es debido a que las disposiciones no tenían que limitarse a los objetos personales del testador y ni siquiera se le requería que fuera un reparto equitativo. Era posible una distribución, entre los sui, del patrimonio entero de forma desigual, de forma que el patrimonio familiar se mantuviera unido. Además, en la mancipatio familiae se podían distribuir probablemente, por primera vez, cuotas de activo neto, que se adquirirían a título particular.

Si seguimos a WIEACKER, cuando resume el ritual, eliminando las palabras que se adhirieron a la fórmula cuando la mancipatio familiae pasó a ser testamentum per aes et libram podemos reconstruir con bastante precisión el acto que se seguía. El familiae emptor iniciaba el rito pronunciando las palabras:

"Familiam pecuinamque tuam endo mandatela custodelaque mea, esse aio eaque hoc aere, aeneaque libra, esto mihi empta...»

Seguidamente, golpeaba la balanza con el trocito de bronce y lo entregaba al testador a modo de precio. A continuación, el mancipio dans entregaba al familiae emptor las instrucciones para la distribución del patrimonio que acababa de transmitir, y pronunciaba las palabras:

"...Haec ita ut in his tabulis cerisque scripta sunt, ita do ita lego itaque vos quirites testimonium mihi perhibetote.»

Todo apunta a que en un primer momento, se expresara oralmente, en el mismo acto de la mancipatio, la voluntad respecto de la distribución del patrimonio mancipado. Si así fuera, en la fórmula originara ita ut in his tabulis cerisque scripta sunt se sustituiría por ITA y los distintos ruegos. 
Además, existiría la figura de los testigos, que tenían una doble función: en primer lugar, su participación era imprescindible para la validez de la mancipatio. Pero en segundo lugar, también servían para atestiguar que se dieron las instrucciones, y, si el mancipio dans había expuesto su voluntad oralmente, ejercían probablemente un cierto control, aunque fuera moral, sobre la actuación del familiae emptor.

No puede darse, por desgracia, más datos acerca de esta forma de organizar el destino de las relaciones jurídicas de un ciudadano romano a su muerte, porque las fuentes son muy poco explícitas.

En relación al testamentum per aes et libram: Este testamento es, sin duda, la producción más relevante de la jurisprudencia pontifical. En este acto se fusionan características de los actos jurídicos mortis causa existentes en la época. Por un lado, se permite al testador conferir de forma inmediata el título de heres universal a la persona que considere más adecuada. Este efecto tenía lugar en el testamentum calatis comitiis, pero ahora se permite testar a todos los ciudadanos romanos púberes, independientemente de que tengan o no descendencia o de que sean patricios o plebeyos.

Por otro, junto a la institución de heredero, que es la esencia del acto, se permite hacer disposiciones a título particular (llamadas legati). El acto mortis causa al que se refiere la frase uti legassit... de las XII Tablas se integra en el testamento per aes et libram y desaparece como negocio independiente.

El testamentum per aes et libram sigue requiriendo para su validez la forma de la mancipatio, pero no debe a la mancipatio familiae más que el ritual. En su contenido y en sus efectos es algo esencialmente distinto. Puede decirse que, sobre los materiales tradicionales, la jurisprudencia pontifical consigue crear un acto nuevo que revolucionará el Derecho sucesorio.

En el testamentum per aes et libram, el testador instituye directamente a las personas que deben sucederlo, los heredes, y ellos serán los encargados de cumplir las demás disposiciones del testamento. El familiae emptor participa en el ritual de otorgamiento pero solo como supervivencia del pasado.

Es más, en las tablillas de cera no aparecen las instrucciones para la distribución del patrimonio, sino que contienen la institución de heredero y las demás disposiciones testamentarias. No se adquieren los bienes, ni tiene que ocuparse de su distribución mediante el testamento. Solo debe estar presente en el momento del otorgamiento para que se consideren cumplidas las formalidades prescritas por el

(C) UNED. Revista de Derecho UNED, núm. 17, 2015 
ius civile. Este testamento permanecerá durante toda la época clásica como el único testamento civil válido.

Fechar el nacimiento del testamentum per aes et libram es una dura tarea, ya que en la época de las XII Tablas ni siquiera existía la mancipatio familiae. Sin embargo, este acto debe ser bastante antiguo, ya que en su fórmula aparece la preposición arcaica endo. Además, no debemos ignorar que el testamento libral tiene todos los rasgos de una creación de los pontífices y posiblemente sea anterior a la publicación de las fórmulas del archivo pontifical a principios del siglo III. En cualquier caso, no es probable que la mancipatio familiae evolucionara hacia testamentum per aes et libram antes del siglo IV A.C. Por otro lado, tenemos numerosos testimonios de que en el siglo II A.C. el testamento libral, con institución de herederos y ordenación de legados, estaba completamente desarrollado. En consecuencia, puede afirmarse que el testamentum per aes et libram vio la luz, con toda probabilidad, entre los años 400 y 200 A.C. Precisamente en esos años debemos buscar el origen de la incompatibilidad entre la sucesión testamentaria y la intestada.

\section{Origen del principio de incompatibilidad entre la sucesión testamentaria e intestada}

La primera mención del principio abstracto se encuentra en De Inventione 2,21,62-64 de Cicerón, una obra escrita entre el 91 y el 87 A.C., pero es indudable que sus orígenes se remontan a tiempos mucho más antiguos, de los que apenas tenemos información fiable. En consecuencia, sobre las circunstancias y el momento en el que nació el principio solo pueden proponerse hipótesis que se fundamenten en exposiciones relativamente tardías del Derecho sucesorio más antiguo.

A pesar de ser muchas las hipótesis en relación a esta problemática, la romanística ha ido perfilando en los últimos años una solución más o menos consensuada de lo que puede entenderse por la evolución más probable del testamento y el principio de incompatibilidad entre la Sucesión Testamentaria e Intestada.

El principio, en sentido literal, quería decir que la sucesión de los «paganos»-entendiéndose por tales quienes no tenían la condición de militares- no se podía deferir en parte por testamento y en parte por la Ley, si bien el espíritu de la norma era la imposibilidad de concurrencia entre herederos testamentarios e intestados. 
La razón por la cual el principio se formulaba respecto a fundamentos sucesorios y no entre títulos sucesorios, se encontraba en el hecho de que el testamento debía contener necesariamente institución de heredero, y dado que si el heredero no llegaba a adquirir efectivamente tal condición el testamento no valía, se establecía una equivalencia entre testamento y heredero efectivo.

La cuestión acerca de la compatibilidad o incompatibilidad entre la sucesión testamentaria y la intestada exige como presupuesto la existencia de un testamentum en el que puedan asignarse cuotas ideales, ya directamente, ya indirectamente a través de la simple institución de una pluralidad de personas.

Tras la exposición de los tipos de testamento (y otras formas de sucesión) que hemos realizado previamente, ahora podemos entender y descartar cual sería el momento exacto de la aparición del principio que tratamos.

En el caso del testamentum calatis comitiis es, en un principio, una adrogación con efectos retardados a la muerte del testador-adrogante. Es improbable que se permitiera la adrogación de una pluralidad de personas y, en cualquier caso, una distribución de cuotas entre los adrogados es totalmente imposible. Aunque el testamento comicial evolucionó para devenir un acto en el que se instituía directamente a un heredero, no es probable que se permitiera nunca la institución de una pluralidad de personas, ni la distribución de cuotas.

En la mancipatio familiae no había institución de heres y, por tanto, podían quedar cuotas sin distribuir (que quizás se quedaba el $f a-$ miliae emptor), pero en ningún caso vacantes.

Por ello, debemos decantarnos por la hipótesis de que el primer testamentum en el que se puede instituir una pluralidad de heredes, $\mathrm{y}$ es posible asignar cuotas es, muy probablemente, el testamentum per aes et libram. Con este testamento debió de surgir, por primera vez en la sucesión testamentaria, el problema de las cuotas vacantes, ya porque uno de los instituidos no pudiera o no quisiera suceder, ya porque el testador no hubiera dispuesto de todo el as.

En consecuencia, puede afirmarse que nuestro principio no puede ser anterior al surgimiento del testamento libral, que, como hemos dicho, debe situarse, probablemente, entre el 400 y 200 A.C. Ésa es la fecha a quo del surgimiento de la cuestión sobre la compatibilidad o la incompatibilidad entre la sucesión testamentaria y la intestada. Los problemas que hemos enumerado se plantean necesariamente en

(C) UNED. Revista de Derecho UNED, núm. 17, 2015 
cuanto nace el testamentum per aes et libram, y los pontífices deben utilizar toda su experiencia para hallar una solución ${ }^{13}$.

BYNKERSHOEK, en sus Observationes, es uno de los primeros en tomar consciencia de este hecho y enfocar la explicación del origen de la incompatibilidad entre la sucesión testamentaria y la intestada en estos términos ${ }^{14}$. Sin embargo, limitado por los conocimientos históricos de su época, no supo extraer las conclusiones precisas que hoy son tomadas en consideración como punto de partida en el estudio del principio.

Es importante entender la prelación de sucesores según la Ley de las XII Tablas en relación a la sucesión intestada, que aplicaba tres órdenes de sucesores: Los sui heredes, los agnati proximi y los gentiles.

Cada uno de estos tres grupos de personas formaba un grupo estanco, de forma que la sucesión debía quedar necesariamente entre los miembros de uno de los grupos y no podían entrar a suceder los miembros de un grupo posterior mientras hubiera alguno del grupo anterior. A modo de ejemplo podemos advertir que si uno de los agnati proximi repudiaba la herencia, no se permitía a los gentiles entrar a suceder en esa cuota, sino que, a través del mecanismo del acrecimiento, aumentaban su cuota los demás agnati proximi (recordemos, además, que en la sucesión legítima civil en Roma no se admite la sucesión en grado). Igualmente, si algún suus heres no podía suceder por falta de lo que los romanistas llaman testamentifactio pasiva (p.ej., había perdido la ciudadanía o había muerto), al fallecer el causante sucedían necesariamente e inmediatamente los sui restantes, y no se defería en ningún momento la cuota de ese suus a los agnati proximi.

El hecho de que los sui heredes sean herederos necesarios e inmediatos y que, por tanto, no puedan dejar vacante una cuota de forma sobrevenida, hace que el mecanismo aísle los dos grupos y solo permita abrir la compuerta para trasvasar la herencia al grupo de los

${ }^{13}$ Para resolver el caso de uno de los instituidos que repudia la herencia o que no puede aceptarla por falta de testamentifactio, los pontífices se encuentran ante una disyuntiva: o bien defieren la cuota vacante a los herederos ab intestado, o bien permiten un acrecimiento proporcional de los demás herederos instituidos en el testamento. Como apunta PEREZ SIMEÓN, para decantarse por una o por otra solución, los pontífices tuvieron que basarse en algo que conocieran. Es seguro que no podían inspirarse en las soluciones de los Derechos vecinos, porque éstos desconocían un testamento con institución de heredero universal como el romano. Tampoco podría ser de gran ayuda los actos de disposición mortis causa más antiguos, ya que el testamento per aes et libram es algo fundamentalmente distinto de lo que le precedió. Más bien parece que debieron dirigir sus miradas hacia una regulación que había tenido que enfrentarse a problemas similares: la sucesión $a b$ intestato.

${ }^{14}$ En la misma línea, FINESTRES I DE MONSALVO. 
gentiles cuando la sucesión en el de los agnati proximi es imposible porque no queda nadie para suceder. Este mecanismo es el acrecimiento.

Con el fin de mantener la «impermeabilidad» del grupo, los pontífices, basándose en el sistema de la sucesión intestada, crearon con el testamento con institución de heredero universal, un nuevo grupo estanco que se antepuso a los de la sucesión intestada, y para ello utilizaremos el sistema del acrecimiento. Si los instituidos en testamento eran sui heredes, el único problema que podía plantearse es que uno de ellos careciera de la llamada testamentifactio pasiva. Si no eran sui, entonces podía plantearse además el caso de que repudiaran. La solución a estos problemas era la misma que se venía utilizando desde hacía siglos para la sucesión intestada: los coherederos del mismo orden acrecen en proporción a su cuota.

Los casos de repudio y de falta de testamentifactio, se dan tanto en la sucesión testamentaria como en la intestada y, en consecuencia, no es de extrañar que se trasladen soluciones de un ámbito al otro. No obstante, hay ciertos casos exclusivos de la sucesión testamentaria y que tuvieron que resolverse recurriendo a la analogía.

Poco después del surgimiento del testamento per aes et libram debió plantearse la cuestión de qué hacer si el testador disponía de más o menos del as hereditario. El primer caso solo permite una solución: La reducción de las cuotas testamentarias. El caso más problemático es la distribución de menos del as. Aquí, los pontífices decidieron, probablemente, por analogía con los casos planteados en el párrafo presente: se aplica a esta cuota vacante por falta de disposición del testador el mismo régimen que a la cuota vacante por repudio o por falta de testamentifactio del instituido. En la opción en favor de aplicar analógicamente el régimen del acrecimiento, el carácter de acto de disposición universal del precedente inmediato del testamentum per aes et libram, la mancipatio familiae, debió desempeñar un papel importante. Con la solución del adcrescere no se permitía que el causante rompiera el sistema de los órdenes estancos jerarquizados disponiendo solo de una parte de su patrimonio, y se mantenía la armonía entre la regulación de las sucesiones testamentaria e intestada.

La jurisprudencia clásica consideraba análogo al caso del testador que distribuye menos de 12/12 el de la nulidad de alguna de las instituciones de heredero. Éste es, con toda probabilidad, el enfoque originario del problema, de forma que, cuando una institución de heredero era nula, se tenía por no escrita y los demás instituidos acrecían esa cuota. 
En un primer momento también debía considerarse nula la institución de heredero en cosa cierta o sometida a término o a condición resolutorios. Los pontífices se encuentran ante una proposición contradictoria: un heres, sucesor universal por definición, no puede limitar su adquisición a una cosa concreta o a un tiempo determinado. La nulidad de este tipo de institución provoca también que la sucesión testamentaria no se compatibilice con la intestada: si hay otros herederos instituidos, sucederán y, si no, se abrirá completamente la sucesión ab intestato.

Las fuentes nos informan de que en el siglo I A.C. la jurisprudencia introdujo soluciones para evitar la nulidad. En esa época, el principio de incompatibilidad entre la sucesión testamentaria y la intestada ya había culminado su proceso de abstracción y tenía, en este ámbito, un valor normativo asentado que restringió junto a otros principios esenciales, como el de la universalidad del título de heredero, la libertad creadora de los juristas.

A partir del momento en el que la jurisprudencia pontifical impuso estas soluciones, puede observarse acertadamente que el testamento queda configurado como un acto de disposición universal, al igual que lo había sido la mancipatio familiae. También puede decirse que el heredero instituido en testamento está abocado potencialmente al todo. Pero estas observaciones son una consecuencia de la decisión tomada por los pontífices, no su causa. Primero fue el acrecimiento y luego la observación de que eso implicaba que el testamentum per aes et libram conservaba el carácter de acto de disposición universal de la mancipatio familiae y de que el heredero tenía una vocación potencial al todo.

Cabe preguntarse qué razones de fondo llevaban a esta jerarquización de los potenciales sucesores en órdenes estancos. Es difícil afirmar con rotundidad qué tenían en mente los creados del orden sucesorio ab intestato de las XII Tablas, que probablemente recoge lo que se venía haciendo de forma consuetudinaria desde tiempos inmemoriales. Es posible que intentaran jerarquizar el grado de vinculación afectiva con el causante: primero los hijos, luego los parientes de vínculo agnaticio más cercanos, y, por último, la familia en sentido amplio, la gens.

Es probable que los pontífices quisieran dar al causante la posibilidad de establecer un grupo de personas más vinculadas afectivamente a él que todas las anteriores, concediéndole la facultad de mezclar sui con extraños, de elegir a los sui preferidos, o incluso de instituir a personas con las que no tenía vínculos de parentesco pero 
con las que tenía una relación afectiva mayor que con los de su propia familia (incluso esclavos). Y para ello crearon el testamento libral.

En la línea de PÉREZ SIMEÓN, creemos que es posible que la razón de fondo que estructuró la sucesión de esta forma fuera la voluntad de mantener la unidad del patrimonio familiar. Sin embargo, algunas de las normas más antiguas del Derecho sucesorio romano que conocemos no parecen preocuparse excesivamente de mantener el patrimonio indiviso.

En las XII Tablas, los heredes sui suceden todos ab intestato por partes iguales, sin distinción de edad ni de sexo. No se conoce, en el Derecho romano privilegio alguno de primogénito, a diferencia de lo que ocurre en numerosos Derechos de la antigüedad (hebreo, japonés, etc.). Algo después de la creación del testamento libral, la introducción de la regla sui aut instituendi aut exheredandi sunt, y el establecimiento de la ruptura del testamento al nacer un póstumo, no reflejan, a nuestro entender, una excesiva preocupación por mantener el patrimonio unido. Con esto no queremos afirmar que los romanos no se preocuparan de frenar la división de la tierra que se produce inevitablemente si todos los hijos heredan por partes iguales. Simplemente consideramos necesario dejar patente que la igualdad entre los hijos era un valor también muy importante para ellos, y que, en ocasiones, era considerado preferible a la concentración del patrimonio familiar.

Otros factores debieron de contribuir a que los pontífices se decantaran por esta solución. Es posible que la estructura o el contenido de los actos de disposición mortis causa anteriores al testamento libral tuvieran cierta importancia en la opción de los pontífices, pero en nuestra opinión, no fueron decisivos. El testamentum per aes et libram representó una novedad radical en la concepción del papel que debía desempeñar la voluntad del causante en la transmisión de sus relaciones jurídicas después de su muerte. Los pontífices eran conscientes de esta novedad, y no nos parece probable que introdujeran en el testamento libral de forma acrítica reminiscencias de actos anteriores.

Por las mismas razones, tampoco es aceptable que un concepto de sucesión que (real o supuestamente) hubiera existido en época arcaica, hubiera sido decisivo para la solución que idearon los pontífices. No creemos tampoco que el tenor literal de la norma de las XII Tablas que reza si intestato moritur... fuera crucial en la opción de los pontífices en favor de la incompatibilidad entre la sucesión testamentaria y la intestada. Es posible que el tenor de la frase les sirviera de apoyo 
para su decisión, pero de ninguna forma ese tenor literal les condujo de forma necesaria a la solución que tomaron.

Muchos romanistas fundamentan el principio de incompatibilidad entre las sucesiones en una interpretación literal de la frase si intestato moritur... Los sui, los agnati proximi y los gentiles solo podrían suceder si el testador muere intestado.

BONFANTE se queja de que justificar el principio en la interpretación literal de las XII Tablas deja por responder la cuestión esencial "Le interpretazioni letterali che possiamo forse riferire all'antico diritto, sono tendenziose, con scopo ben definito: queale era qui lo scopo?».

Y de esta manera, la sucesión intestada se mantiene dividida en órdenes estancos a lo largo de toda la historia del Derecho romano y, por tanto, la ratio que llevó a establecer la incompatibilidad, para los casos que estamos tratando aquí, se mantuvo, y no se reputó imprescindible una reforma general. Esto generó que una solución nacida en época arcaica sobreviva a lo largo de toda la evolución del Derecho romano porque perdura la ratio por la que nace.

A modo conclusivo, lo que hemos expuesto es que son necesarios dos presupuestos para que se plantee el debate sobre la compatibilidad o incompatibilidad entre la sucesión testamentaria y la intestada: debe existir un testamento en el que se pueda instituir a un heres universal y en el que quepa la posibilidad de que existan cuotas hereditarias vacantes.

Por ello, el primer acto jurídico a considerar que reúne estas dos características es el testamentum per aes et libram.

La aparición de este testamento provocó nuevo conflictos: Una cuota hereditaria podía quedar vacante porque el instituido repudiara o porque no tuviera testamentifactio pasiva. Los pontífices resolvieron este caso por analogía con lo que ocurría en circunstancias idénticas, en la sucesión ab intestato de los agnati proximi: al igual que cuando un agnado próximo no podía no quería suceder, su cuota no se defería a los gentiles, sino que acrecían los demás agnati proximi, así también cuando un instituido se encontraba en esas circunstancias, el mecanismo del acrecimiento cerraba el paso a los sucesores $a b$ intestato. Los pontífices extendieron esta solución a los demás casos de vacancia de una cuota hereditaria exclusivos de la sucesión testamentaria. De esta forma, la introducción del testamentum per aes et libram mantuvo intacta la estructura de órdenes estancos que caracterizaba la sucesión de las XII Tablas. 
A partir de las soluciones expuestas y, probablemente, del tratamiento originario del problema de la institución de heredero en cosa cierta, se abstrajo, en algún momento de los siglos III-II a. C., el principio general de la incompatibilidad entre la sucesión testamentaria y la intestada. Este principio general se formulaba, probablemente, de formas muy diversas hasta que, hacia mediados del siglo II d. C. se generalizó una formulación estándar que, con más o menos variantes, solía ser utilizada por los juristas de la época cuando querían citar el principio como ratio decidendi de un caso. La característica esencial de esta formulación estándar es que el principio se enfocaba desde la perspectiva del testador, del que no podían predicarse simultáneamente los dos adjetivos testatus e intestatus.

Las soluciones a problemas concretos que hemos expuesto tienen en común impedir en todo caso que una persona pueda tener sucesores testamentarios y $a b$ intestato. En algún momento que desconocemos, entre el nacimiento del testamento libral y el año 100 A.C. se abstrae, a partir de la solución que los pontífices habían dado a estos casos, el principio general de que la sucesión testamentaria es incompatible con la intestada.

Por otra parte, la generalización de una forma regular de enunciar el principio tuvo lugar en un momento relativamente tardío, y no debe tomarse como punto de referencia para fechar su contenido jurídico. La regularidad con la que se forma el principio, tampoco puede servir de parámetro para determinar su valor normativo, ya que un principio puede tener una fuerza normativa importante sin que nunca llegue a cuajar en una formulación regular.

Por consiguiente, si se desea estudiar el valor normativo de un principio, no basta con analizar las fuentes en las que aparece citado expresamente, sino que es imprescindible estudiar todos los textos en los que pueda descubrirse su aplicación implícita. Por ello, como hemos visto y tras la exposición de los tipos de testamento que fueron apareciendo en época preclásica y clásica podemos concretar en qué momento se dio la problemática y a partir de ello, en qué momento tiene lógica que empezaran a darse soluciones mediante el principio formulado.

\section{LA EVOLUCIÓN EN EL DERECHO CASTELLANO DEL PRINCIPIO NEMO PRO PARTE}

Desde los inicios, la doctrina clásica castellana discutió la vigencia o no del principio nemo pro parte. Sin embargo, la evolución del prin-

(C) UNED. Revista de Derecho UNED, núm. 17, 2015 
cipio del Derecho en Castilla fue admitiendo la compatibilidad entre herederos testamentarios e intestados, lo que culminó con el art. 658.3 del Código Civil español de 1889, que ya de manera taxativa admitió que la sucesión podía deferirse en parte por testamento y en parte por la Ley.

Toda la problemática acerca de la vigencia o no del principio derivaba de la existencia de un dogma que había perdurado por inercia desde la época clásica y que no se ajustaba a los tiempos medievales y modernos que precedieron. La vigencia del principio en las Partidas se deducía de la solución que se daba al heredero en cosa cierta. La Ley XIV del título III, Partida VI, establecía que:

«En una cosa señalada, así como en viña ó en otra cosa cualquier, establesciendo un home á otro por su heredero, si en este mesmo testamento ó en otro que ficiese después el testador non fallasen que hobiese otro establescido por heredero, este atal debe haber todos los bienes del testador, maguer fuese establescido en una cosa señalada tansolamente; pero las mandas del testamento débelas cumplir así como las fallaren hi escriptas. Et si por aventura el testador ficiese despues otro heredero, entonce aquel deximos desuso que era establescido en la cosa señada, debe esa haber tan solamiente: et todos los otros bienes deben fincar al otro que fue después establescido. Otrosi decimos que si dos homes fuesen establescidos por herederos en un testamento, el uno en una cosa et el otro en orta señada, si el facedor del testamento non departiese nin mandase dar á otri los otros bienes que hobiese, estos amos los deben haber todos igualmente, et cada uno dellos debe haber ante aquella cosa en que fue esatblescido por heredero; pero amos de so uno son tenudos de responder á las debdas del facedor del testamento. Et si por aventura el testador establesciese en una cosa señalada por heredero á un home, et á dos ayuntamientos en otra cosa cierta, si non mandase los otros bienes, débenlos habes estos herederos partiéndolos entre sí de esta manera, la meatad á aquel que fue establescido en la una cosa, et la otra meatad á los dos que fueron establescido en la otra, fueras ende si el facedor del testamento dixiese que heredasen todos egualmiente; pero cada uno destos debe haber adelantada aquella cosa en que fue establescido por heredero» (Fragmento de Las Siete Partidas del Rey Don Alfonso X el Sabio).

Desde el siglo XVI al XIX los juristas castellanos mantuvieron vigente esta discusión doctrinal acerca de la aplicación o no del principio puesto que no quedaba fijado si después del Ordenamiento de Alcalá y de la Novísima Recopilación se mantuvo en Castilla la vigencia de los principios romanos recogidos en las Partidas -y en concreto, del principio nemo pro parte-, dado que la Ley $1 .^{a}$ del título XIX del citado Ordenamiento -que posteriormente pasó a ser la Ley 1. ${ }^{a}$, título II Libro V del Ordenamiento Real de Castilla o de MONTALVO, del títu- 
lo IV, libro V de la Nueva Recopilación, y del título XVIII del libro X de la Novísima- estableció que:

«... y mandamos que el testamento que en la forma susodicha fuera ordenado, valga en cuanto a las mandas y otras cosas que en él se contienen, aunque el testador no haya hecho heredero alguno; $y$ entonces herede aquel que según derecho y costumbre de la tierra habia de heredar en caso que el testador no hiciere testamento, y cúmplase el testamento...»

Este precepto reafirmaba la falta de necesidad de la institución de heredero para la validez del testamento y, por tanto, si el heredero no aceptaba no debía por ello quedar ineficaz en su conjunto con todas las disposiciones que lo formaban. Por ello, siempre que se aceptase la vigencia del principio nemo pro parte, se debía reformular de una manera distinta a la del Derecho romano, de manera que, como sucedía en los territorios de Barcelona y Tortosa, la incompatibilidad se producía no entre testamento y sucesión intestada, sino entre herederos testamentarios y legales.

Así lo entendieron algunos juristas castellanos, pero otros incluso fueron más lejos, al considerar que la citada Ley Primera del Título XIX del Ordenamiento de Alcalá había derogado no tan solo el principio de la necesidad de institución de heredero para la validez del testamento, sino también el resto de principios que constituían la base del sistema sucesorio romano, entre ellos el principio nemo pro parte.

Finalmente, la versión mayoritaria dentro del ius commune fue la consideración de que la incompatibilidad se producía no entre testamento y sucesión intestada, sino entre herederos testamentarios y legales y ello generó que la doctrina castellana, hasta bien entrado el siglo XIX produjera una animadversión a aplicar principios del Derecho romano, basándose en su atemporalidad.

En los siglos XVI y XVII, aún la mayoría de los autores castellanos del ius commune consideraban todavía vigente el principio nemo pro parte, si bien, como decíamos, tal opinión no era unánime.

Por otra parte, entre los autores que defendían la posición minoritaria conforme a la cual el Ordenamiento de Alcalá derogó los principios romanos recogidos en las Partidas, se encuentra PICARDUS, quien sostenía que,

"Alià deinde huius regulae limitatione por talios notat DEC. In d.l. oius nostruú n.12 videlicet. Si ita municipali, lege cautu sit, ut possit quis pro parte testatus et pro parte intestatat decedere, que a MINSING, hic referutr $n$. si. Unde infertur quod cum hodie attenta lege 1. Tit. 4 lib. 5 recop. Possit quis decedere pro parte testatus, et pro parte intestatuts, 
instituts in re certa eam tantumodo rem consequetur, non vero universam hereditatem, quia cessat ratio, propeter quam reliqua bona certa rei institution extenditur, intelliguntur que eo casu ex tacita mente defuncti in reliquis bonis venientes ab intestestato vocati. Quam sententiam nominatim resoluit MATIEN. In d.l.l. glos.10.nu.46.tit.4.lib.5.recop.quem videas.»

Por el contrario, en dicha época, la mayoría de la doctrina mantenía la subsistencia de la regla nemo pro parte. Entre quienes afirmaban expresamente la no derogación por el Ordenamiento de Alcalá de los principios sucesorios romanos puede citarse AYLLON LAYNEZ, quien después de afirmar que a pesar de que un grupo de autores entendieron que el Derecho romano fue modificado en esta cuestión por la Ley Primera del Título XIX del Ordenamiento de Alcalá, la opinión más consistente era que dicha Ley no corrigió la Ley romana

Si ex fundo: "An autem dispositio text. In 1.2. Parraf. Si ex fundo, ff. De heredibus instituendis, de quo hic, sit correcta per 1.1. titul.4 lib. 5. Recop. Et eam ese correctam, et reliqua bona pertinere ad venientes ab intestato, iuxta dispositionem dicta legis I. docent MATIENZO ibídem glossa 10. Ex num. 46. Et alii, et cum eir PICHARDUS, in parraf. Haereditas, Institut. De haeredibus instituendis, num. 36. Et CEVALLOS quaest. 214. Quasi per totam. Caeterum probabilius, et verius est, dictam l. I parraf. Si ex fundo, non ese correctam per l.1, ut docuit MOLINA de primogeniis lib. I, cap. 17, num.23. TULLUS FERNÁNDEZ in 1.3. taur.3.part.num.2.seipsum corrigens CEVALLOS quastione 753, n.50. AZEVEDUS in dicta l.1. num.163 et melius PICHARDUS se etiam corrigens in repetitione titul. Ff. De vulgari substitutione, cap. 4, ex un. 87, et in relectione ad titulum, ff. De acquirenda haereditate, cap. 30, num 29, et seq. Ubi num. 30 addit, quid si testator praeceperit, ut haeres nominatus eam rem habeatt, et non amplius? Eum vide. Tenet etiam JOANNES GRATIANUS eleganter in regul. 281, n.8 CASTILLO in lib. 3. Controvers. Cap. 17. Et D. LARREA decis. 40, un, 10. Et 68, SALGADO in labyrintho I, part. Cap. 2, parraf. Único, num 17».

En cualquier caso, en el siglo XVIII aún quedaban autores que entendían vigente el principio nemo pro parte, entre ellos, Josef FEBRERO, que después de señalar que en virtud de la Ley primera, titulo cuarto, libro quinto de la Recopilación el testamento era eficaz a pesar que no se designase heredero o éste no aceptase la herencia, afirmó que el instituido en cosa cierta, si no se designaba heredero universal, debía hacer suya por derecho de acrecer la totalidad de los bienes, "pues de no heredarlos todos, se verificaría que el Testador moría en parte testado, y en parte intestado, lo cual repugna».

Sin embargo, con la entrada del S. XIX, la segunda de las opiniones tomó fuerza y al Derecho romano como un derecho ajeno a la sociedad, y que, por tanto, en la medida de lo posible, había de ser recha- 
zado. La mayoría de los juristas compartían la derogación del principio nemo pro parte por el Ordenamiento de Alcalá. Pero no solo se limitó al principio que nos ocupa, se pretendió eliminar todo rastro del Derecho romano de los códigos, por atemporal y alejado de la realidad contemporánea.

SAHAGÚN DE MARFÁ Y DE QUINTANA lo describía con estas palabras «...hubo algunos que, aficionados al estudio del Derecho Romano... quisieron romanizar nuestro derecho. Por eso nuestros legisladores, que nunca le han concedido un lugar en nuestros códigos, quisieron poner coto á los estravios de los jurisconsultos Españoles, derogando espresamente la tal jurisprudencia».

Entre los pocos autores que defendían la subsistencia del principio nemo pro parte, se encontraba DE TAPIA, quien, en su Febrero novísimo, defendió la vigencia del mencionado principio.

DE TAPIA se ocupó de la regla de la incompatibilidad al tratar el heredero en cosa cierta y la cláusula de contentamiento. Respecto al primero, afirmó que si no se ha designado heredero universal, el heredero en cosa cierta percibirá el resto de bienes hereditarios «no por derecho de acrecer sino por virtud y extensión de la institución». Y en cuanto al caso en que el testador no solamente no disponía de todos los bienes, sino que además prohibía expresamente que acreciesen al heredero en cosa cierta, señalaba que «sin embargo de la prohibición se le acrecerán por necesidad de derecho: porque el testador no puede prohibir ni impedir que las leyes tenga fuerza y vigor contra su disposición, ni contra el derecho de acrecer, para que no muera en parte testado e intestado".

Por tanto, DE TAPIA se limitó a afirmar la vigencia del principio nemo pro parte, pero sin abordar la cuestión en profundidad, y sin tratar la cuestión de si tal principio fue no abolido por el Ordenamiento de Alcalá. Y, en todo caso, reconoció que «entre nosotros no se observa el rigor de aquel principio».

En cambio, la gran mayoría de autores de los siglos XVIII y XIX, entre ellos, GÓMEZ DE LA SERNA, GUITERRA, SAHAGÚN DE MARFÁ, MORCILLO MURO, HERNÁNDEZ DE LA RUA, FALCÓN, o MARTÍ DE EIXALÀ, consideraron que el principio nemo pro parte ya no seguía vigente en Castilla, basándose en la mencionada Ley primera, título XVIII, libro X de la Novísima Recopilación.

Eran perfectamente esclarecedoras al respecto las palabras de SALA quien afirmaba que:

"Entre las leyes Romanas había una muy famosa que decía no poder morir un testado, y parte intestado... Pero el de d. célebre l.l. tit. 18.lib.10 
de la Nov. Rec... convence que arruinó y corrigió este decantado axioma de los Romanos. Podrá pues en España morir uno parte testado y parte intestado.»

En el siglo XIX, la mayoritaria doctrina castellana era favorable a la compatibilidad entre la sucesión testada y la intestada -recogida por el Tribunal Supremo en algunas Sentencias-, fue la que adoptaron los redactores de los sucesivos proyectos de Código Civil español, incluyendo el de GARCIA GOYENA, quien calificó el principio nemo pro parte de «sutil» y «riguroso", y señaló que "Causa asombro leer en la 7 de "Diversis Regulis Iuris: Earumque rerum naturaliter inter se pugna est testatus et intestatus», repetida en el párrafo 5, título 14, libro 2, Instituciones, cuando en el mismo se esceptúan los testamentos militares, como si lo que es natural no debería obrar igualmente en todos".

Por todo ello, parece coherente que el Código civil español de 1889 tratase de manera clara e indubitada la abolición del principio nemo pro parte. El art. 658.3 dispone que la sucesión «Podrá también deferirse en una parte por disposición del hombre, y en otra por disposición de la ley», y el art. 764 dice que "El testamento será válido aunque no contenga institución de heredero, o ésta no comprenda la totalidad de los bienes, y aunque el nombrado no acepte la herencia o sea incapaz de heredar. En estos casos se cumplirán las disposiciones testamentarias hechas con arreglo a las leyes, y el remanente de los bienes pasará a los herederos legítimos». Se trata de un sistema que, en general, mereció el juicio favorable de la doctrina comentadora del Código civil.

En este sentido, MUCIUS SCAEVOLA hablaba de una norma «destructora, con muy buen criterio, de las sutilezas romanas y creadora de un estado de derecho más conforme con la naturaleza humana y con los predicados de justicia y conveniencia social». Y SÁNCHEZ ROMÁN señalaba que el fundamento de ambas sucesiones era la voluntad del difunto, expresa en la testada y presunta en la intestada, lo que propiciaba «la perfecta compatibilidad ó coexistencia de las dos especies de sucesión testada o intestada, atendida la homogeneidad de su raíz jurídica».

\section{LA COMPATIBILIDAD E INCOMPATIBILIDAD ENTRE LA SUCESIÓN TESTAMENTARIA Y LA INTESTADA EN EL ORDENAMIENTO JURÍDICO ESPAÑOL ACTUAL}

A finales del siglo XIX y en curso el proceso de codificación legislativa en Europa, la alteración del sistema sucesorio de derecho romano no afectó en todos los territorios de la península de igual manera. 
El Código Civil español de 1889 no derogó el Derecho propio catalán, sino que preveía su conservación mediante unos apéndices en los que se recogiesen sus especialidades. Pero mientras tales apéndices no se aprobasen, seguían vigentes las leyes civiles catalanas y su propio Derecho supletorio, por lo cual permanecía inalterado el régimen jurídico vigente antes de la publicación del Código. En consecuencia, en materia sucesoria, seguía vigente el principio Nemo pro parte. Así lo señalaba de manera clara BORREL I SOLER:

"La sucessió intestada podría completar la testamentaria quan el testador no disposa de tot el patrimoni o en queda vacant una part; però, per raons históriques, el D. R. no permet que, dins una mateixa successió, hi hagi hereus testamentaris i intestats: "nemo paganus pro parte testatus, pro parte intestatus decedere potest», i aixó s'aplica a Catalunya.»

Con la excepción legislativa de la Segunda República, el principio se ha mantenido vigente en Cataluña hasta la regulación del Código de Sucesiones Catalán. Como podemos observar en el Preámbulo del texto, se basa ante todo en el respeto a la tradición jurídica catalana: «La presente Ley sustituye y modifica parcialmente la tradición jurídica reciente... No se modifican, por lo tanto, los grandes principios propios del Derecho Romano, tan arraigados en el Derecho sucesorio catalán... Estos principios, arraigados en la tradición y hoy vivos en la aplicación del Derecho en Cataluña, se mantienen integramente, dada la inexistencia de suficientes justificaciones de orden jurídico, social o práctico que hagan aconsejable su modificación, aunque sea parcial».

Sin embargo, hay otras justificaciones como la del principio de universalidad de la sucesión hereditaria. MARTI I MIRALLES equiparando «totalidad» $\mathrm{y}$ "universalidad», decía que «...si l'hereu testamentari ho és en la totalitat o universalitat del patrimoni del difunt, és evident que no pot quedar res que sigui trasmès per título d'intestatura...». Desde esta perspectiva, era evidente que un heredero testamentario no podía concurrir con un heredero intestado.

Pero ¿qué consecuencias acarrea la perpetuación del principio nemo pro parte?

El significado del principio nemo pro parte ha cambiado en el Código de Sucesiones respecto al que tenía en la tradición jurídica. Sin embargo, dicha alteración del significado no se ha acompañado de una revisión de las consecuencias de tal principio.

La consideración de los herederos intestados como legatarios de parte alícuota en el caso de caducidad parcial de la confianza ya es una consecuencia del principio nemo pro parte. El párrafo $7 .^{\circ}$ del Preámbulo del Código de Sucesiones cita otras: el incremento heredi- 
tario y la consideración que se confiere al heredero en cosa cierta, al heredero vitalicio y al heredero en usufructo, si bien guarda silencio respecto a la eficacia de la cláusula de contentamiento, que no se regula en el Código de Sucesiones.

Y es que la regula iuris decía "Nemo pro parte testatus pro parte intestatus decedere potest», y tenía su lógica. Si el heredero era considerado como un sucesor en la personalidad jurídica del difunto, y lo sucedía en todo su patrimonio, en el caso en que llegase a ser heredero efectivo no podía darse entrada a los herederos intestados, dado que nada quedaba por disponer por vía de intestatura. Y, por otra parte, si la eficacia del testamento dependía de la aceptación del heredero testamentario, se producía una equivalencia entre testamento y heredero efectivo, de manera que la relación de incompatibilidad se podía formular no solamente entre herederos testamentarios e intestados, sino también entre testamento y sucesión intestada.

Como apunta BOSCH CAPDEVILA, en el Derecho vigente, en cambio, el principio nemo pro parte ya no tiene el mismo significado que en la tradición jurídica, ni puede decirse que venga impuesto por la propia naturaleza de las cosas, es decir, por la imposibilidad de que alguien a la vez, sea y deje de ser una misma cosa (heredero en nuestro caso). Si se permite la institución hereditaria en una cuota de la herencia, la inicial «universalidad total» inherente al título de heredero ya queda rota, y la expansividad de aquel título no es una exigencia sino una opción legal. La eficacia del testamento, a pesar de la falta de aceptación del heredero permite desvincular testamento y heredero, y el principio se reformula como incompatible de títulos, no de fundamentos sucesorios.

Pero es que, además, en el Código de Sucesiones Catalán se abren importantes brechas en el principio nemo pro parte. Si el fundamento del principio nemo pro parte se traspasa de la Ley a la voluntad del testador, no todas las que el párrafo VII del Preámbulo del Código de Sucesiones cita como consecuencias de aquel principio quedarían sin efecto. Tanto el incremento hereditario, como la consideración del heredero en cosa cierta, el heredero vitalicio y el heredero en usufructo, podrían mantenerse, partiendo de la presunción legal de que la voluntad del testador se halla en aquel sentido, pero debería admitirse la declaración y la prueba en contrario.

Esto crea la aparición de numerosas excepciones en la aplicación del Derecho Sucesorio catalán, y si atendemos a lo referido al inicio del presente estudio, pueden dividirse en la aplicación de diversos principios, no solo la incompatibilidad del Nemo Pro Parte: 
- En relación al principio de universalidad del título del heredero (Hereditas nihil aliud est quam sucesio in universum ius quod defunctus habet): El heredero es el sucesor universal del causante. Es decir, está llamado a la totalidad del patrimonio hereditario, con carácter expansivo y absorbente mediante el acrecimiento. Sin embargo, no es necesario que el heredero sea único ni que haya de adquirir todos los bienes del causante, pueden ser varios y puede ser compatibilizado con los legados.

En cualquier caso, existe una posible excepción en caso de distribución de los bienes de la herencia en legados y la aceptación a beneficio de inventario. En el primer caso, el causante podría repartir la mayor parte de la herencia en legado, dejando al heredero como una figura testimonial que únicamente tendría derecho a la legítima y a la cuarta falcidia. En el otro caso, la aceptación a beneficio de inventario impide que el heredero asuma las obligaciones del causante y, por tanto, el heredero no responde con el patrimonio propio de las obligaciones del causante, sino que se liquida previamente el caudal relicto y el heredero recibirá el excedente positivo.

- En relación al principio de la unidad del título sucesorio (Nemo Pro Parte). Este principio establece la incompatibilidad simultánea de diferentes fundamentos sucesorios. Además, tiene una importante consecuencia práctica y es la obligación de acrecimiento. En este sentido, si el heredero testamentario solamente es instituido en una parte de la herencia, la parte restante no es considerada intestada, sino que acrece al heredero.

La incompatibilidad entre el testamento y la sucesión intestada es absoluta, y lo mismo sucede entre el heredamiento y el abintestato (STSJ, de 13 de marzo de 1995).

La primera incoherencia en relación a este principio es que permite afirmar que es posible la coexistencia de la sucesión voluntaria (codicilo) y la sucesión legal, en cambio, es incompatible el nombramiento de un heredero por vía voluntaria y por vía legal.

Además, si lo comparamos con otros ordenamientos, la compatibilidad de los diferentes fundamentos sucesorios es más respetuosa con la voluntad del causante. Este principio lleva a interpretaciones forzadas de algunas figuras como la del heredero en cosa cierta (art. 423.3 CCCat), el heredero en usufructo cierta (art. 423.5 CCCat) y por tanto, este principio distorsiona la voluntad del causante. 
- En relación a la perdurabilidad del título sucesorio (Semel heres, Semper heres). El art. 423.12 CCCat establece que el qui es hereu ho es sempre $i$, per tant, es tenen per no formulats en la institució d'hereu la condició resolutòria i el terminis suspensiu $i$ resolutori. Lo que genera diversas consecuencias legales: En primer lugar, no se puede instituir heredero bajo término suspensivo ni resolutorio, ni esta última de manera particular. Pero por otra parte, sí se puede instituir heredero bajo condición suspensiva, porque no hay persona que pierda dicha cualidad del heredero.

Por estas razones genera dos excepciones clarísimas: La sustitución fideicomisaria y pacto reversional en l'heretament. Es decir, permite una amplia crítica a que la aplicación del principio Semel heres, Semper heres es muy poco respetuosa con la voluntad del causante.

Como hemos visto, para la correcta aplicación de los principios que conforman la armonía romana en relación al Nemo Pro Parte (Semel Heres, Semper Heres y la Universas) deben concretarse una suerte de excepciones específicas, tal vez excesivas y numerosas que complican la aplicación del sistema sucesorio en la actualidad. Además, hay que añadir que las personas sujetas al Derecho de Tortosa no se ven afectadas por estos principios puesto que pueden distribuir toda la herencia en legados sin necesidad de establecer institución del heredero y por otro lado, si se nombra un albacea universal (marmessor universal) se permite otorgar testamento válido sin institución de heredero (puesto que hay una persona encargada de dar cumplimiento a la voluntad del causante).

La disputa y la crítica se han polarizado en razones culturales e identitarias más que en razones pragmáticas. Ello genera que la aplicación del principio tenga serios problemas de fundamentación si los comparamos con la legislación nacional.

LUCAS ESTEVE razona que los principios tradicionales del derecho civil catalán han de estar presentes en el ordenamiento jurídico como han estado durando siglos, sirviendo perfectamente con la función de ordenar el Derecho de Sucesiones Catalán. Este conjunto de principios presenta excepciones, algunas de ellas importantes, pero que no pueden minar la continuidad de los principios. Contestando a FERRER: «el dret català ha optat per perservar uns principis que l'han singularitzat histporicament a costa de la racionalitat del sistema» apunta que considera importante mantener los principios por ser válidos y tener ventajas y desventajas como tantos otros principios del derecho. Reconociendo que el mantenimiento de los principios obliga 
a la aparición de excepciones o forzar determinadas interpretaciones, la abolición crearía problemas diferentes que no necesariamente harían más sencillo el proceso sucesorio. Por ejemplo: la posibilidad de otorgar un testamento sin heredero comporta tantos problemas prácticos que la exigencia del heredero, como se demuestra en las legislaciones en las que no es necesario dicha institución.

Tal vez la solución al debate pase por determinar cuál era la presumible voluntad del testador, sin imponer una solución basada en un principio fundamentado simplemente en razones de política legislativa. Confiar en que el animus del testador es cumplido pues, después de todo, es su herencia y legado a los que se quedan.

\section{CONCLUSIONES}

Hasta la introducción del testamentum per aes et libram no puede plantearse la disyuntiva entre la compatibilidad e incompatibilidad de las sucesiones. Faltan los presupuestos necesarios, que introducirá el testamento libral: posibilidad de que el testador instituya a más de un heredero y de que distribuya cuotas entre ellos.

La introducción del testamento libral provocó la aparición de una serie de problemas nuevos, que tuvieron que ser solucionados por los pontífices. Una cuota hereditaria podía quedar vacante porque el instituido repudiara o porque no tuviera testamentifactio pasiva. Los pontífices resolvieron este caso por analogía con lo que ocurría en circunstancias idénticas, en la sucesión ab intestato de los agnati proximi: al igual que cuando un agnado próximo no podía no quería suceder, su cuota no se defería a los gentiles, sino que acrecían los demás agnati proximi, así también cuando un instituido se encontraba en esas circunstancias, el mecanismo del acrecimiento cerraba el paso a los sucesores ab intestato. Los pontífices extendieron esta solución a los demás casos de vacancia de una cuota hereditaria exclusivos de la sucesión testamentaria. De esta forma, la introducción del testamentum per aes et libram mantuvo intacta la estructura de órdenes estancos que caracterizaba la sucesión de las XII Tablas.

Por otra parte, el Testamentum calatis comitiis permitía la institución de heres, pero parece improbable que el testador pudiera instituir a varias personas y, mucho menos, asignar cuotas. En este tipo de testamento no cabía a nuestro entender, tampoco la posibilidad de ordenar disposiciones a título particular. Podían legarse los bienes personales en un acto independiente, que se fundamentaba en la nor- 
ma decenviral uti legassit... No creemos que en el testamento comicial pueda hablarse de cuotas o de legados, porque esta forma testamentaria es, con toda probabilidad, una evolución a partir de la adrogatio, de la que nunca llegó a separarse de forma absoluta. Probablemente sólo se permitía testar a los patricios que no tenían hijos, y el testamento consistía simplemente en designar un sucesor, un heres.

La mancipatio familiae no es un testamento. Es una forma de organizar el destino de los bienes para después de la muerte que prescinde absolutamente de la figura del heres. En consecuencia, el debate acerca de la compatibilidad o incompatibilidad entre las sucesiones es imposible.

Así pues, la introducción, en los siglos IV-III A.C., del testamento libral provocó el nacimiento de una serie de problemas que hasta entonces eran desconocidos en la sucesión testamentaria. Por primera vez, podía haber pluralidad de instituidos y, en consecuencia, cuotas vacantes por repudio o por falta de testamentifactio de alguno de ellos. Este problema no era nuevo en el Derecho sucesorio. Se daba ya en la sucesión $a b$ intestato de los agnados próximos. Si uno de los agnados repudiaba o no tenía testamentifacción, los demás acrecían. Los pontífices tomaron esta sucesión como modelo y aplicaron el mismo régimen a los sucesores testamentarios. Si uno estaba en las circunstancias mencionadas, también tenía lugar el acrecimiento.

Además, el testamentum per aes et libram planteaba también problemas nuevos. Podía ser que el testador distribuyera menos de 12/12. Para este caso, se optó por aplicar, por analogía, la solución que acabamos de ver para los demás supuestos de vacancia de una cuota: las proporciones asignadas se aumentaban proporcionalmente.

Otro conflicto que se planteó con el testamento libral fue el de instituciones nulas entre las que se contaban muy probablemente la institución de heredero en cosa cierta, o bajo término o condición resolutorios. En estos casos, si había herederos instituidos válidamente, tenía lugar el acrecimiento como cuando el testador no había dispuesto de alguna cuota. Si todas las instituciones eran nulas, el testamento no valía por carecer de su caput et fundamentum y, en consecuencia, se abría completamente la sucesión intestada.

Sabemos que el siglo i a. C. la jurisprudencia estaba haciendo esfuerzos para sanar algunas de estas cláusulas, pero todos los expedientes ideados serán respetuosos con los principios esenciales del Derecho sucesorio tradicional, incluido el de incompatibilidad entre la sucesión testamentaria y la intestada. 
En definitiva, los pontífices utilizaron sabiamente la experiencia acumulada en el régimen de la sucesión intestada para resolver los problemas provocados por la introducción de un acto nuevo, el testamentum per aes et libram. La sucesión seguía manteniendo su estructura básica tradicional, de compartimentos estancos. El testamento comicial había introducido un grado preferente a todos los demás para un único instituido. Ahora, con el testamento libral, ese compartimento preferente puede albergar una pluralidad de personas, de forma que los sui no pueden suceder mientras haya herederos testamentarios, los agnati proximi tampoco podrán hacerlo mientras haya sui, y los gentiles heredaran si no hay agnatai proximi.

A partir de las soluciones expuestas y, probablemente, del tratamiento originario del problema de la institución de heredero en cosa cierta, se abstrajo, en algún momento de los siglos III-II A.C., el principio general de la incompatibilidad entre la sucesión testamentaria y la intestada. Este principio general se formulaba, probablemente, de formas muy diversas hasta que, hacia mediados del siglo II d. C. se generalizó una formulación estándar que, con más o menos variantes, solía ser utilizada por los juristas de la época cuando querían citar el principio como ratio decidendi de un caso. La característica esencial de esta formulación estándar es que el principio se enfocaba desde la perspectiva del testador, del que no podían predicarse simultáneamente los dos adjetivos testatus e intestatus.

La generalización de una forma regular de enunciar nuestro principio tuvo lugar en un momento relativamente tardío, y no debe tomarse como punto de referencia para fechar su contenido jurídico. La regularidad con la que se forma el principio tampoco puede servir de parámetro para determinar su valor normativo, ya que un principio puede tener una fuerza normativa importante sin que nunca llegue a cuajar en una formulación regular. Por consiguiente, si se desea estudiar el valor normativo de un principio, no basta con analizar las fuentes en las que aparece citado expresamente, sino que es imprescindible estudiar todos los textos en los que pueda descubrirse su aplicación implícita.

Los autores del ius commune apuntaban, si bien no de una manera clara ni sistemática, las consecuencias del principio nemo pro parte, señalando que tal principio constituía el fundamento de reglas de derecho sucesorio tales como:

- La imposibilidad de que el testador prohibiese el derecho de acrecer.

- El carácter forzoso del acrecimiento hereditario. 
— La imposibilidad de morir con más de un testamento válido.

- Que el testamento no podía ser en parte válido y en parte inválido.

- Que al heredero no le era permitido aceptar parcialmente la herencia ni tampoco quedarse con la legítima y repudiar el resto de la herencia.

Pero las dos consecuencias más importantes del principio eran el acrecimiento entre «disjuntos», así como respecto a la parte de herencia de que el testador no había dispuesto, y el efecto expansivo de la institución ex re certa cuando no había otros herederos instituidos sin tal asignación.

Dicho principio pasó a nuestra legislación mediante un proceso de inercia de la tradición, si bien durante la edad media y la época moderna hubo un proceso importante de relajación del principio, dos fueron las razones por las cuales el mismo comenzó a desaparecer del general de recopilaciones legislativas peninsulares:

La versión mayoritaria dentro del ius commune fue la consideración de que la incompatibilidad se producía no entre testamento y sucesión intestada, sino entre herederos testamentarios y legales y ello generó que la doctrina castellana, hasta bien entrado el S. XIX produjera una animadversión a aplicar principios del Derecho romano, basándose en su atemporalidad. Por otra parte, otro sector consideró que el Ordenamiento de Alcalá había derogado el principio y por tanto no debía de tenerse en cuenta en posteriores recopilaciones.

Sin embargo, en la actualidad, podemos ver cómo el principio se ha mantenido en el Código de Sucesiones Catalán, al socaire de una razón histórica y de perpetuación de la tradición. Esta decisión del legislador catalán no toma en consideración la atemporalidad del principio y es que, además, en el Código se abren importantes brechas en el principio nemo pro parte. La compatibilidad entre herederos instituidos en diferentes testamentos, o entre un heredero testamentario y uno contractual, atenta contra la pretensión de exhaustividad de cada fundamento sucesorio. Y, si se admite la compatibilidad entre herederos llamados por diferentes fundamentos voluntarios por razón de su complementariedad, ¿por qué no admitir también la compatibilidad jurídica entre herederos legales cuando también la compatibilidad material? Si se respondiese que en la sucesión intestada falta la voluntad del testador, se estaría reconociendo que el principio nemo pro parte, más que de la Ley, debe derivar de 
aquella voluntad del testador, con lo cual no debería operar si se demostrase que su voluntad es contraria al incremento hereditario.

Por todo ello, no podemos sino declararnos en contra del mantenimiento, descafeinado y totalmente anacrónico de un principio que ya ha quedado superado por la doctrina y la jurisprudencia, que no tiene una aplicación práctica en la época contemporánea y que no se ajusta a los estándares generales de una legislación común.

\section{BIBLIOGRAFÍA}

\section{Manuales y monografías}

ARIAS RAMOS y ARIAS BONET. Derecho romano, Obligaciones, Familia, Sucesiones, vol. II, 18. . ed., Madrid 1994.

ALBADALEJO (Dir.) y SALVADOR CODERCH. "Comentarios a los artículos 248 a $241 \mathrm{CC}$ a Comentarios al Código Civil y Compilaciones Forales, T. 29, vols. I y III y T. XXL, Madrid, Editoriales de Derecho Reunidas, S. A., 1991.

BOSCH CAPDEVILA. El principio Nemo pro parte testatus pro parte intestatus decedere potest. Evolución y significado. Dykinson. 2006.

- «Carta o testamento?, Comentario a la STSJC n. ${ }^{\circ}$ 27, 16.9.2002» Working Paper de Dret Català n. ${ }^{\circ}$ 6. INDRET Barcelona. 2003.

CANNATA. Historia de la ciencia jurúidica europea, Madrid, 1996 (traducción de Histoire de la jurisprudence européenne, vols. 1 y 2, 1989).

D’ORS. «Aspectos objetivos y subjetivos del concepto de ius», en Studi Albetario, vol. II, Milán, 1953.

D’ORS, A. HERNÁNDEZ TEJERO, FUENTESECA, GARCÍA GARRIDO y BURILLO. El Digesto de Justiniano, Pamplona, 1972.

FERNÁNDEZ BARREIRO y PARICIO. Fundamentos de Derecho privado romano, 2. ${ }^{a}$ ed., Madrid. 1993.

GÓMEZ ROYO. «El testamento militar en las fuentes jurídicas romanas y griegas» en Estudios homenaje a Valls i Taberner, vol. XVII, Barcelona, 1991.

HERNÁNDEZ TEJERO. Historia e instituciones de Derecho romano, Madrid, 1949. 
LACRUZ. Elementos de Derecho civil, V (Derecho de sucesiones), Zaragoza, 1988.

LAMBERT. La tradición romana sobre la sucesión de formas del testamento ante la historia comparada, Madrid, 1901.

LUCAS ESTEVE. «Els principis del dret sucessori català», Dret Civil Català, Vol. III. J. M. Bosch, Barcelona, 2010.

MIGUEL MASOT. «Artículo $7 .^{\circ}{ }^{\circ}$. Comentario al Código Civil. VLEX.

MURGA. Derecho romano clásico. II, El proceso, Zaragoza. 1980.

PÉREZ SIMEÓN, Nemo Pro Parte Testatus Pro Parte Intestatus Decedere Potest. El principio de incompatibilidad, entre la sucesión testamentaria y la intestada en el Derecho Romano. Marcial Pons, Barcelona, 2001.

RASCÓN. Manual de Derecho romano, 2. a ed., Madrid, 1996.

RIBAS-ALBA. «Una pretendida controversia entre Papiniano-Ulpiano y Paulo: en torno a D.5,2,19 (Paulo 2 quaest.) y una hipótesis sobre la legítima», en Iura, núm. 39 (1988).

RODRIGUEZ DE FONSECA. Digesto teórico-práctico o recopilación de los Derechos cómun, real y canónico por los libros y títulos del Digesto, vol. 18, Madrid, 1791.

VALIÑO. Actiones útiles en Instituciones de Derecho privado romano, Valencia, 1977.

VARELA. «La escasa viabilidad de la sucesión testamentaria en época arcaica», en Estudios Ursicino Álvarez, Madrid, 1978, págs. 535 y ss.

\section{Fuentes}

Institutiones en Fontes iuridicae romanae anteiustinianeae (FIRA), 2. ${ }^{\text {a }}$ ed.

MOMMSEN. Corpus Iuris Civilis, Vol. I, Berlín, 1905.

KRÜGER. Corpus Iuris Civilis, Vol. 2, Berlín, 1884.

\section{Resoluciones consultadas}

STSJC de 13 de marzo de 1995.

STSJC de 16 de septiembre de 2002. 